\title{
SOME ELEMENTS OF SPECIFICITY OF THE MARKETING IN THE HEALTHCARE FIELD
}

\author{
Laura Cătălina Ţimiraş \\ University "Vasile Alecsandri" of Bacau, \\ timiras.laura@ub.ro
}

\begin{abstract}
The present paper aims to present some of the specific aspects of marketing in the healthcare field (with strict reference to the products intended for human consumption), in relation to other fields. After a presentation of the fields of marketing applicability in the healthcare, a series of specific elements are presented regarding the nature of the motivations underlying the decision to consume / use a medical product and the elements of appreciation of their value by the final consumers (patients), along with aspects regarding price, distribution and communication. In general, the specificity of the marketing activity is given by the category of products targeted ideas, tangible goods / services intended for the consumer market, products intended for the business markets, which print certain particularities as appropriate: social marketing, marketing of consumer goods, the marketing of services or business-to-business marketing, as well as the specific needs that these products address, the role of the prescribers in manifesting this behavior or the regulations in the field that aim to protect public health.
\end{abstract}

\section{Keywords}

healthcare marketing; medical products; customer value; purchase motivation; price; communication; distribution

\section{JEL Classification}

M31; I12; I18

\section{Introduction}

The marketing of healthcare products for human consumption (especially those distributed at the level of consumer markets) has multiple particularities compared to other fields of application, a fact determined by the specific needs which they address, by the role of the prescribers, by the regulations in the field that have the purpose of protecting public health etc. Referring to the differences between marketing in the healthcare field in relation to other fields of application of marketing Crié, D., Chebat, J.C. (2013) stated that patient is not a regular consumer, and the rationalities of the actors and the functioning of the markets differ from many points of view.

Based on information presented in the marketing literature, this paper aims to present some of the specific elements of marketing in the health-related field, referring to medical services and tangible products (prescription drugs, OTC - medicines can be purchased without a prescription, medical devices, equipment etc.).

\section{Categories of products in the healthcare field}

At the market level, medical products can be found in a variety of forms. For example, referring to the product offered by non-governmental organizations whose purpose is to defend and promote the rights of patients with various conditions, this will be represented by all the ideas for which the respective organization militates in the direction of increasing the public's adherence to those ideas; the products offered by a 
clinic are materialized in all the consulting services offered, medical investigations, etc. possibly offered by certain doctors / personalities in the medical field, as well as the conditions / environment in which these services are provided, respectively the characteristics of the equipment used etc.; the product offered by a spa complex will consist of all the consultations and recovery services offered, the hotel services and the public catering, including even the natural and anthropic resources of the spa resort where the complex is located and which the clients can benefit from; the product offered by a manufacturer of medicines and medical devices constitutes the totality of the medicines and devices manufactured; the product offered by a company whose activity is the physical distribution of medical equipment is represented by all the transport, storage, handling services, etc. as well as advice, assistance in use, etc. that the respective organization offers.

\section{Applicability of marketing in the healthcare field}

Due to the diverse nature of the healthcare products and the heterogeneity of the operators in this field, the importance of health for the population, the way of conducting transactions, etc. the applicability of marketing in the field of healthcare knows a multitude of valences. In fact, the use of social marketing to promote socially beneficial behavior change in the public health field has increased. (Grier, S., Bryant, C.A., 2005). Thus, the marketing activities carried out in the healthcare field can be included in the: social marketing, services marketing, consumer goods or business to business to marketing; each of the marketing specializations listed with multiple features that operators in the respective markets must take into account.

According to Brătucu G. (2003) marketing in the field of healthcare or "healthcare marketing" is a component of social marketing that seeks to raise awareness among the general public about the danger of spreading different diseases, promoting "health" through health education and reducing the number of illnesses. The actions specific to the healthcare marketing target both the healthy and the sick, being differentiated strategies of action for each of the two categories of public. A separate category of strategies are the "demarketing strategies" that are used for products such as alcohol, tobacco, drugs whose consumption can affect the health of the population, in order to counteract the actions of the organizations that promote them and to reduce / eliminate the consumption as appropriate. them. Healthcare marketing actions are generally practiced by private organizations for philanthropic, cultural or charitable purposes, as well as public administration bodies, the challenges faced by the initiators of health campaigns being (according to Randolph, W., Viswanath, K. , 2004) those to attract the attention of the targeted public in the context of the multitude of messages at which they are exposed at all times, as well as to find those motivations able to change behaviors (with an impact on the state of health) often rooted or, as the case may be, to determine new habits, sometimes difficult to adopt.

Regarding the marketing activities aimed at the medical services (offered in hospitals, clinics, individual medical offices, etc.) they fall within the scope of service marketing, the medical service providers following through the marketing actions undertaken to increase the customer value of the services offered and to satisfy the expectations of the clients. / patients. So, referring to a hospital, Kotler (1998) specified that "a marketingminded person will want to know where the patients come from, why they appeared at this particular hospital, and how they feel about the hospital care and services". The application of marketing in medical services has intensified with increasing competition between healthcare providers and with the growing awareness regarding the role of patient satisfaction for the development of the organization and, implicitly, in achieving a distinctive competency as Wagner et al (1994) suggested: "building relationship with patients is critical to the success of many health care organizations". 
Also, the marketing activities carried out by the operators in the markets of equipment, devices, medical supplies and pharmaceuticals fall within the sphere of business to business marketing or, as the case may be, the marketing of consumer goods depending on the consumer / end-user - organization (hospitals, clinics, medical offices, etc.) or individual (as a patient) to whom they are addressed. As in the case of the medical services market, the increase of the number of operators and the intensification of the competition required the companies to increase the customer value of the offered products in order to increase the level of satisfaction of the consumer / user and thus to maintain / develop at the reference market level.

\section{Some specific elements about customer value and motivation behind the decision of consumption / use of medical products}

Referring to the medical products and considering that in the concept of marketing a product exists only by reference to a certain market, its specific elements are presented by reference to the final consumer; differences from this point of view, notably existing at the level of the consumer markets and, to a lesser extent, the business ones.

In marketing terminology, the customer value of the products refers to the difference between the perceived utility and the perceived cost (Boier, 2006), the subjective elements predominating in the appreciation of the value in the case of most products, and the motivation behind the purchase decision is often an emotional one. In this context, at the level of consumer markets, in the design and development of new products an essential role is played by the research of the psychological motivations of consumers. However, referring to the medical products precisely because of the need to which they are addressed (the consumer will consume / use a medical product in general only if the state of health requires it), the motivation underlying the decision of consumption / use is rational and not emotional, and, often, it does not belong to the final consumer (but to the prescriber: doctor, pharmacist). Thus, at this market level the process of developing new products is predominantly the result of the research innovation approach in research laboratories and to a lesser extent the research on consumer motivations. On the other hand, the rational motivation underlying the consumption / use of a certain medical product, concerns the category and not the product / service itself (product brand). For example, the decision to go to the doctor is triggered by objective causes, but the doctor / clinic chosen can be based on subjective elements (prestige of the medical staff, the environment etc.). Similarly, the administration of a certain drug (referring to its active substance) may have a rational motivation, but the product (brand) may be based on subjective factors (brand awareness, previous favorable experience / brand confidence, appreciation of product presentation etc.); this applies both to OTC (when the decision may belong to both the prescriber and the patient) and even to prescription drugs (in which case the decision belongs exclusively to the doctor). Therefore, in close relation to the aspects presented, the role that emotional, subjective aspects can play in customer value assessment (perceived utility vs. perceived costs) should not be excluded, though, compared to a wide range of other consumer products, the objective elements are important in the appreciation of value by consumers. For example, referring to the value perceived by the patient of a medical consultation, its usefulness can be appreciated both on the basis of functional benefits (the efficiency of the treatment prescribed for the medical problem in question), but also emotional (confidence given by the prestige of the clinic, the feelings of satisfaction generated by the behavior of the medical staff). On the other hand, the cost charged is given both by the price of the consultation, the expenses related to the transport, other expenses occasioned by the consultation, respectively expenses generated by the return to control etc., as well as by other "expenses" not quantified in money: feelings of frustration, anxiety etc. (generated, for example, by the lack of respecting of the scheduling time or by the inappropriate 
behavior of the reception staff, etc.). Similarly, taking the case of a drug, its usefulness is given, on the one hand, by the efficiency in treating the diseases to which it is addressed, by the possible minimal adverse effects, etc. (useful in a functional nature), but also the confidence in the manufacturer, appreciation of the way the product is presented, etc. (emotionally useful); and the cost of this will be given both by the price of the product, as well as by other expenses occasioned by the purchase of the product, by the price of any recommended products to be administered together for the reduction of adverse effects etc., but also by feelings of anxiety generated by the administration of the product, for example.

In the context presented, and with increasing competition and reaching the maturity by the markets, when the differentiation between products is increasingly difficult to achieve, the different operators at the market level place a greater emphasis on the emotional benefits. For example, taking the case of medical services, differentiating between providers based on the functional characteristics of the services offered (specialties, categories of investigations, technical characteristics / performances of the used equipment, staff training level, tariffs, etc.) is increasingly difficult to achieve, case in which the medical operators place a special emphasis on the emotional benefits: the comfort given by the pleasant environment in which the medical services are provided - furniture, arrangement, cleaning etc., appropriate signage (reffering to hospital services), Vigolo, V., Bonfanti, A.,Sallaku, R., Douglas, J., 2020, specifing that "signage has a positive and significant effect on satisfaction") etc., diminishing anxiety and increasing the confidence in the services offered by the way the staff interact with the patient, his / her level of involvement, discretion, accessible manner in which all the necessary / requested information and explanations are provided; / explanations received during the period of progress etc. Thus, referring to the role of communication between the doctor and the patient in the assessment of the medical act, Alicja, L.F. (2018) appreciate that the meetings and discussions between the two directly influence the effectiveness of the healthcare received by the patient, generally the patients giving greater importance to the personal characteristics and communication skills of the doctor than the professional competences required.

The same author Alicja, L.F. (2018), using information from the specialized literature (Nowina Konopka M., 2016 and Wróblewska I., Steciwko A., 2013), indicates the factors that she considers essential in the communication of the doctor-patient: focus on the patient and not on the problem; the involvement of the doctor in relation to the patient; the physician's behavior as a humanitarian professional, manifesting empathy; treating the patient with respect; adopting the role of "patient teacher"; maintaining the connection and listening to what the patient says.

Even at the level of the medical equipment market, a market that presents the characteristics of the business market, the evaluation of the products being carried out mainly according to objective criteria (the technical characteristics of the products), we do not exclude the role of the subjective, emotional elements in the differentiation of the products and, implicitly, in the decision to buy. For example, in the case of two similar medical equipment in terms of the technical characteristics and the price, the confidence given by the manufacturer's prestige, the (perceived) ease of use of the equipment, or, as the case may be, a more efficient communication with the supplier can make the difference.

Beyond the elements underlying the appreciation of the customer value of different products and, implicitly, the decision to purchase, it should be mentioned that for a significant part of the medical products, the regulations in the field limit the freedom of choice of the consumers (as for example, the medicines delivered on prescription (Crié, D., Chebat, J.C., 2013), which is a peculiarity of the market for these products. 


\section{Some specific elements about marketing communication regarding medical products}

In terms of communication, it has many particularities compared to other categories of goods resulting from the legislation in force, as well as the specificity of the purchasing decision process.

Referring to the legislation, there are multiple provisions that refer to medicines. Thus, at community level, Directive 2001/83/EC of The European Parliament and of The Council of 6 November 2001 on the Community code relating to medicinal products for human use and the subsequent amendments, regulates the advertising of medicinal products for human use, by advertising understanding "any form of door-to-door information, canvassing activity or inducement designed to promote the prescription, supply, sale or consumption of medicinal products; it shall include in particular: the advertising of medicinal products to the general public, advertising of medicinal products to persons qualified to prescribe or supply them, visits by medical sales representatives to persons qualified to prescribe medicinal products, the supply of samples, the provision of inducements to prescribe or supply medicinal products by the gift, offer or promise of any benefit or bonus, whether in money or in kind, except when their intrinsic value is minimal, sponsorship of promotional meetings attended by persons qualified to prescribe or supply medicinal products, sponsorship of scientific congresses attended by persons qualified to prescribe or supply medicinal products and in particular payment of their travelling and accommodation expenses in connection therewith"

According to this document, any advertising for a medicinal product for which a marketing authorization has not been granted is forbidden. Advertising should encourage the rational use of the drug, by its objective presentation, without exaggerating its therapeutic qualities and without misleading.

Advertising for the general public and for the professionals in the field, is subject to different provisions. Referring to advertising for the general public, it is forbidden for drugs that are issued on prescription or those containing substances defined as psychotropic or narcotic. The information provided must comply with the information listed in the summary of product characteristics. The direct distribution of drugs to the public by the companies in the field for promotional purposes is also prohibited.

Advertising intended for the general public must be designed so that the advertising character of the message is clearly visible, and the product clearly identified as a medicine; it must also contain the information necessary for the correct use of the medicine and an explicit and legible invitation to read carefully the instructions in the package leaflet or the outer packaging, as appropriate. Advertising for a drug intended for the general public should not contain any material that: gives the impression that a medical consultation or surgery is not required; to suggest that the effects of drug administration are guaranteed and are not accompanied by adverse reactions or are better or equivalent to those of another treatment or drug; to suggest that the health of the user may be improved by the administration of the drug or may be impaired if the drug is not administered (excluding vaccination campaigns); be intended exclusively or mainly for children; to refer to a recommendation of a recognized personality that could encourage drug use; could lead to misdiagnosis; to make claims about healing, in inappropriate terms, alarming or misleading, etc.

In the case of advertising for professionals able to prescribe / deliver medicines, the advertising must contain essential information according to the summary of the product characteristics as well as the category in terms of how the product is delivered. The product samples can only be distributed to persons qualified to prescribe them, being accompanied by a copy of the summary of the product characteristics;

The Directive also specifies the information to be found on the label of medicinal products. 
According to the same document, the Member States must ensure the monitoring of advertising and they may also establish additional regulations in this area.

In Romania, for example, the advertising of medicines for human use is monitored by the National Agency for Medicines and Medical Devices (NAMMD). According to Order no. 194/2015 regarding the approval of the Norms for the evaluation and endorsement of advertising for medicinal products for human use, all advertising materials intended for the general public / patients are, prior to being placed on the market, approved by the NAMMD. The same document specifies that advertising for the general public through social networks or mobile applications, as well as advertising information to the general public containing promotional offers or references to discounts, price reductions, special prices is prohibited. Also, outdoor advertising or any form of advertising presented on communication channels, other than pharmacies, medical offices, audiovisual field, print media, internet is prohibited.

Beyond the conditions that must comply with, the communication for medical products must also take into account the particularities of the purchasing decision-making process. Thus, in the market of medical products intended for final consumers, they often do not coincide with the people who make the purchase decision, an essential role in this respect being the prescriber - doctor / pharmacist. Consequently, frequently on the market of medical products for final consumers, the target of communication is represented by the doctor / pharmacist (as their prescribers) and not the final consumer (the patient), in the context in which patients are not able in most situations to identify the product they need for a particular condition, as well as the fact that most of the products are released only based on the prescription issued by the doctor. The initiators of the communication process must take into account the particularities of the two categories of target audience, for the same product the communication from the perspective of the techniques used, the channels, respectively the messages may differ depending on the category of receivers. For example, taking the case of a new pharmaceutical product for the consumer market that can be purchased without a prescription, the communication may target both the patient and the prescriber.

The communication addressed to patients will generally present the specific characteristics of the communication on the consumer market (in compliance with the regulations in force), between the techniques used, the advertising (through various channels: TV, radio, internet, etc.), having a privileged position. In terms of advertising, emotional and factual elements can be combined (considering the nature of the need to which the product is addressed and, implicitly, the fact that the decision to purchase the product category is based mainly on objective elements). The communication addressed to the prescribers will be realized mainly by means of the recommended techniques to be used in the business markets, respectively: sales forces, print advertising (the topic of communication, being a factual nature, indicating the product characteristics), events addressed to professionals in the field.

\section{Some specific elements about price of medical products}

Referring to the price of medical products, particularities compared to other markets are generated mainly as a result of the policy of clearing medicines and settlement of medical devices and services for patients. Thus, patients are rarely aware of the actual price / cost of the services they buy because they bear this cost only partially (Crié, D., Chebat, J.C., 2013).

For example, referring to medicines, there are regulations in the EU regarding prices and reimbursements depending on their role and how they are used in the health system. In Romania, the prices of medicines that are issued on the basis of a medical prescription are regulated (their maximum prices are set), and the prices of the drugs that are issued without a medical prescription are freely set and modified (Norms regarding the calculation method and the approval procedure of the maximum prices of 
medicines for human use, 2017). Regarding the prices of medicines we mention the price difference between innovative (reference) and generic drugs. Thus, according to information provided by the Association of Manufacturers of Generic Medicines in Romania (2019), the prices of generic drugs are lower with values between $20 \%$ and $90 \%$ compared to the prices of the reference drugs. Innovative or reference medicines are those which enjoy legal protection through the patent. Generic drugs represent the therapeutic equivalent of innovative drugs, having the same composition and can be produced after the expiration of their latter patents. The differences between the prices of the two categories of drugs are to some extent justified by the costs of production; the research and development expenses related to the innovative product generating this gap.

Beyond the differences generated by the production costs (of which consumers are more or less aware), the higher prices of innovative (compared to generic) medicines represent an image of the brand / manufacturer's notoriety, consumer confidence in the respective products for which have a certain experience (generic drugs are produced after 10-15 years from the appearance of the reference medicine), to the entire communication system that accompanies the product on the market. Starting from the aspects presented, at the level of the pharmaceutical market the meaning of the term "generic" associated with a drug, should not be confused with the meaning of the notion of generic associated with the brand, according to the marketing concept. According to Vrânceanu, D. (2003), a generic brand is a brand that has lost its ability to differentiate the product from its competitors, having a common noun value.

For the category of medical products in which prices are freely formed, they have the specific characteristics of the reference market - the consumer market or the business market. Thus, at the level of the business markets, the price is not, in general, a trigger element of the purchase decision (except in the case of standardized products, with identical terms and conditions of delivery), being practically outdated from the perspective of the importance in making the decision to buy the characteristics technical and functional products (Nichifor, 2012). In contrast, at the level of the consumer markets, the price is also an element of differentiation and segmentation of the market according to the criterion of income, higher revenues being generally associated with the orientation towards more expensive products, with a higher customer value from the perspective of the objective elements and, often subjective. On the other hand, the influence that the price level exerts on the purchase decision in the case of consumer markets is only valid for those products in which the consumer / patient does not benefit from compensations / settlements resulting from the available state or private insurance.

\section{Some specific elements about distribution of the medical products}

There are also strict rules regarding the distribution of medical products and services. Beyond these regulations, from a marketing perspective, the distribution presents the specific characteristics of the product category to which it refers - tangible goods / services intended for consumer markets, respectively, products intended for business markets. For example, referring to the medical services market, the distribution channel is generally a direct one, the provider (the doctor / medical staff) providing the patient service directly. It should be mentioned that the depth of the distribution channels may differ, depending on the nature of the medical services, these are generally provided within the medical units (located at a greater or lesser distance from the patient), but can also be provided at the patient's home. (the channel being thus very deep). In the market for goods for final consumers (medicines, medical devices, except for the very expensive ones and whose consumption is rare, as is the case, for example, so-called orphan drugs designed to treat rare diseases), the distribution is usually extensive one (the products are sold through a large number of pharmacies), aiming to be as close as possible to the place of consumption. Regarding the distribution of equipment of 
consumables etc. distribution to organizations (clinics, hospitals, individual medical offices) the distribution generally presents the characteristics of the distribution on the business market. Thus, in general, the products are marketed through short and small indirect channels; and when the product encompasses a high technological level, being therefore more complex, large and / or with a high unit value, it is marketed through direct channels (Nichifor, 2012). On the other hand, the standard products of small size and with a low or medium unit value are traded within the indirect distribution channels.

\section{Conclusions}

Medical products and services are found at the market level in a variety of forms, from communication campaigns aimed at promoting the health of the general public, to medical equipment incorporating a high technological level for organizations specialized in medical services, the product category in which they fall into (ideas, tangible goods / services for the consumer market, products for the business markets), printing the marketing activity with certain particularities as appropriate: social marketing, marketing of consumer goods, marketing of services or business to business marketing. Also, specific elements of the marketing activity regarding medical products result from the specific needs that these products address, with an impact on the consumer behavior as a whole, the role of the prescribers in manifesting this behavior, as well as from the regulations in the field that have the role of to protect the health of the population.

\section{References}

Alicja, Ł.F. (2018), Media as an environment of the modern patient and medical care institutions - management of communication in medicine - selected tools and marketing strategies, Zeszyty Naukowe Ochrony Zdrowia. Zdrowie Publiczne $i$ Zarzadzanie; Kraków Volume 16, Issue 1, pages: 47 - 54.

Armstrong, G., Kotler, Ph. (2015), Marketing: an introduction, Twelfth edition, Pearson.

Baalbaki, I., Ahmed, U.Z., Pashtenko H.V., Makarem S. (2008), Patient satisfaction with healthcare delivery systems, International Journal of Pharmaceutical and Healthcare Marketing, Volume 2, No. 1, pages: 47-62.

Bernhardt, M.J. (2006), Improving Health Through Health Marketing, Preventing Chronic Disease, Volume 3(3), available at: https://www.ncbi.nlm.nih.gov/pmc/articles/PMC1636721/.

Boier, R. (2006), Cercetarea de marketing - o abordare conceptuală, in Boier, R., Ţimiraş, L., Cercetarea de marketing (pages: 17 - 28), Iaşi, Editura Performantica.

Brătucu, G. (2003), Marketing sanitar, in Florescu, C., Mâlcomete, P., Pop, N.A. (coord.), Marketing. Dicționar explicativ (pages: 432 - 433), Editura Economică, București.

Crié, D., Chebat, J.-C. (2013), Health marketing: Toward an integrative perspective, Journal of Business Research, Volume 66, Issue 1, pages 123-126.

Fox, K.F., Kotler, P. (1980), The marketing of social causes: the first 10 years, Journal of marketing, Volume 44, pages: 24-33.

Grier, S., Bryant, C.A., 2005, Social Marketing in Public Health, Annual Review of Public Health, Volume 26:319-339, pages: 319-339.

Kotler, P. (1998), A generic concept of marketing, Marketing Management, Volume 7, Issue. 3, pages: 48-54. 
Kowalik, I. (2006), Marketing Strategies of Health Care Providers in Poland, An Enterprise Odyssey. International Conference Proceedings, Zagreb, pages: 1553-1564.

Nichifor, B. (2012), Business to business marketing, Editura Alma Mater Bacău, 2012.

Randolph, W., Viswanath, K. (2004), Lessons Learned from Public Health Mass Media Campaigns: Marketing Health in a Crowded Media World, Annual Review of Public Health, Volume 25, pages 419-437.

Steven A.T. (1994), Distinguishing service quality from patient satisfaction in developing health care marketing strategies, Hospital \& Health Services Administration, Volume 39, Issue 2, pages: $221-236$.

Tăerel, A-E (2018), Publicitatea medicamentelor de uz uman, Univers farmaceutic. Revista farmaciştilor din România, available at: http://www.universfarmaceutic.ro/amfiteatru/Publicitatea-medicamentelor-deuz-uman.

Vigolo, V., Bonfanti, A.,Sallaku, R., Douglas, J. (2020), The effect of signage and emotions on satisfaction with the servicescape: An empirical investigation in a healthcare service setting, Psychology and Marketing, Volume 37, Issue 3, pages: 408-417.

Vrânceanu, D. (2003), Marcă, in Florescu, C., Mâlcomete, P., Pop, N.A. (coord.), Marketing. Dicționar explicativ (pages: 374 - 376), Editura Economică, București.

Wagner, H.C, Fleming, D., Mangold, W.G., LaForge, R.W. (1994), Relationship marketing in health care, Journal of Health Care Marketing, Volume 14, Issue 4, pages: $42-47$.

Asociatia Producătorilor de Medicamente Generice din România (2019), Campanie de informare, available at: http://www.medicamente-generice.ro/?page_id=26.

European Medicines Agency (2016), Sistemul european de reglementare pentru medicamente. O abordare unitară a reglementării în domeniul medicamentelor în Uniunea Europeană, available https://www.ema.europa.eu/en/documents/leaflet/european-regulatory-systemmedicines-european-medicines-agency-consistent-approach-medicines_ro.pdf.

Directive 2001/83/EC of The European Parliament and of The Council of 6 November 2001 on the Community code relating to medicinal products for human use, and the subsequent amendments available at: https://eur-lex.europa.eu/legalcontent/RO/TXT/?uri=celex:02001L0083-20121116.

Norme privind modul de calcul și procedura de aprobare a prețurilor maximale ale medicamentelor de uz uman, din 28 martie 2017, available at: http://legislatie.just.ro/Public/DetaliiDocument/187804.

Ordinul nr. 194 din 23 februarie 2015 privind aprobarea Normelor pentru evaluarea şi avizarea publicităţii la medicamentele de uz uman, available at: https://www.anm.ro/_ORDINE/ORDIN\%20194.pdf. 